Int. J. Dev. Biol. 54: 1107-1115 (2010)

doi: $10.1387 /$ ijdb.093054lw

\title{
Transcription factor interplay during Drosophila haematopoiesis
}

\author{
LUCAS WALTZER* ${ }^{*}$ VANESSA GOBERT, DANI OSMAN and MARC HAENLIN* \\ Centre de Biologie du Développement, CNRS, Université de Toulouse, Toulouse, France
}

\begin{abstract}
Transcription factors play a key role in regulating blood cell fate choice and differentiation. In this review, we examine current knowledge of the function and mode of action of the transcription factors implicated in haematopoiesis in Drosophila. We particularly emphasize regulation by transcription factors and cofactors, such as GATA, FOG and RUNX, whose homologues in mammals also control blood cell formation and we discuss the cross talks between these transcriptional regulators at the different stages of haematopoietic cell fate decision.
\end{abstract}

KEY WORDS: Drosophila, haematopoiesis, transcription

\section{Introduction}

Over the last few years, Drosophila has emerged as a valuable model system to gain insights into several aspects of blood cell formation. In particular, despite the evolutionary distance between drosophila and vertebrates, many key players controlling blood cell development have been conserved. For instance, transcription factors of the RUNX, GATA or EBF family, as well as signalling from the JAK/STAT, Toll/NF- $\mathrm{KB}$ or Notch/CSL pathways, which play key roles in haematopoiesis in vertebrates, also control blood cell development in Drosophila (Hartenstein, 2006). Transcription factors play a pivotal role during development as they establish the gene expression programmes intrinsic to cell diversification. The aim of this review is to draw the emerging picture of the transcription factors network implicated in Drosophila blood cell development.

Briefly (for details, see the accompanying reviews by Crozatier et al. and Banerjee et al.), haematopoiesis in Drosophila occurs in two waves: blood cell progenitors arise from the head mesoderm in the early embryo and from a specialised organ, the lymph gland, in the larva. These progenitors (prohemocytes) give rise to three differentiated cell types (collectively called hemocytes), which most closely resemble vertebrate myeloid lineages: plasmatocytes, crystal cells and lamellocytes. The plasmatocytes constitute around $95 \%$ of the blood cell population and function as macrophages. The crystal cells participate in melanisation, an insect-specific defence response involved in wound healing and encapsulation of foreign invaders. Finally, the lamellocytes are only produced under particular conditions to encapsulate bodies too large to be phagocytosed.

So far, we have a better understanding of the transcriptional network controlling blood cell development in the embryo than in the larva. Accordingly, we shall present in details the molecular and genetic characteristics of the different transcription factors controlling embryonic haematopoiesis. Then, we shall give an overview of the other transcription factors and cofactors that have been shown to participate more specifically in larval haematopoiesis. Alongside, we shall discuss their function and mode of action in Drosophila haematopoiesis as compared to vertebrates.

\section{The GATA transcription factor Serpent and its friend U- shaped}

The Drosophilagene serpent (srp), which encodes a transcription factor of the GATA family, was the first gene described as implicated in blood cell formation in this organism (Rehorn et al. 1996; Sam et al. 1996). GATA transcription factors are so called because they bind to the consensus DNA sequence WGATAR (Yamamoto et al. 1990; Ko and Engel, 1993; Merika and Orkin, 1993; Whyatt et al. 1993;). They form a small, evolutionarily conserved, family of transcription factors and one of their most conspicuous and best-studied functions is during blood cell formation (Haenlin and Waltzer, 2004). In mammals, three of the six GATA genes (GATA-1, -2 and -3) control different aspects

Abbreviations used in this paper: Gcm, glial cells missing; lz, lozenge; ush, ushaped; srp, serpent.

\footnotetext{
*Address correspondence to: Lucas Waltzer or Marc Haenlin. Centre de Biologie du Développement, Université de Toulouse, 118 route de Narbonne, 31062 Toulouse, France. Fax: +33-5-6155-6507. e-mail: waltzer@cict.fr ; haenlin@cict.fr
} 
of'haematopoiesis from stem cell emergence to differentiation into various lineages (Shimizu and Yamamoto, 2005). In Drosophila, among the 5 GATA genes, only srp appears to directly participate in haematopoiesis but it is reiteratively used at several stages, from blood cell fate specification to terminal differentiation.

Molecularly, GATA factors are characterized by the presence of a highly conserved zinc finger with the characteristic Cys-X2Cys-X17-Cys-X2-Cys spacing followed by a short basic region. In vertebrates, all GATA factors contain two distinctive GATA zinc fingers separated by 29 amino acids and referred to as the $\mathrm{N}$ finger and the C-finger, respectively. The $\mathrm{C}$-finger, which is present in all GATA factors, mediates high affinity binding to WGATAR DNA sequences (Evans and Felsenfeld, 1989; Martin and Orkin, 1990; Omichinski et al. 1993). The $\mathrm{N}$-finger is dispensable for DNA binding but it stabilises the interaction to tandem and palindromic GATA sites (Trainor et al. 1996; Trainor et al. 2000;). The $\mathrm{N}$-finger also mediates the interaction with members of the Friend of GATA (FOG) family such as U-shaped (Ush) (Haenlin et al. 1997; Tsang et al. 1997). So far, all the functions of the FOG family members seem to depend on a GATA factor. In mouse, FOG-1 behaves as a transcriptional coactivator or corepressor in a context-dependant manner (Fox et al. 1999; Pang et al. 2006; Tsang et al. 1997; Wang et al. 2002) and it is required with GATA-
1 for erythro/megakaryocytic differentiation (Tsang et al. 1998). Importantly, several missense mutations in the N-finger of GATA1 affecting its binding to FOG-1 and/or to DNA are associated to red blood cell disorders in human (Cantor and Orkin, 2005). In Drosophila, ush, which is mainly expressed in the plasmatocytes, also participates in haematopoiesis (see below). Actually, srp codes for different isoforms generated by alternative splicing, which contain only a C-finger $(\mathrm{SrpC})$ or both a $\mathrm{C}$ - and an $\mathrm{N}$-finger (SrpNC) (Waltzer et al. 2002). These isoforms are coexpressed in the embryo, but their relative abundance at the protein level is not known. Nevertheless, they exhibit both specific and common properties during haematopoiesis (Waltzer et al. 2002). For instance, SrpNC activates more efficiently than SrpC the expression of $\mathrm{gcm}$ (see below), which contains palindromic GATA sites in its promoter. On the opposite, SrpC activates the expression of the apoptotic body receptor croquemort (crq), while SrpNC represses its expression by recruiting Ush as a corepressor. However, beside Ush-induced phenotypes that are attributable to its interaction with SrpNC (Fossett et al. 2001; Waltzer et al. 2002; Fossett et al. 2003; Sorrentino et al. 2007), the exact contribution of each isoform to the global srp function in blood cell development remains to be clarified.

Indeed, srp is first required for blood cell specification. In the early embryo, srpexpression defines the anlage of the embryonic

A

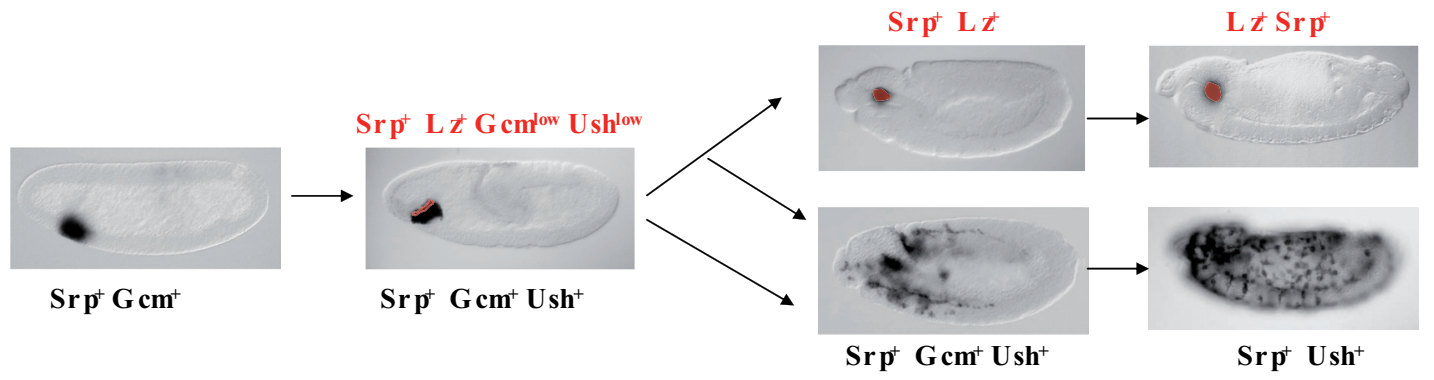

B
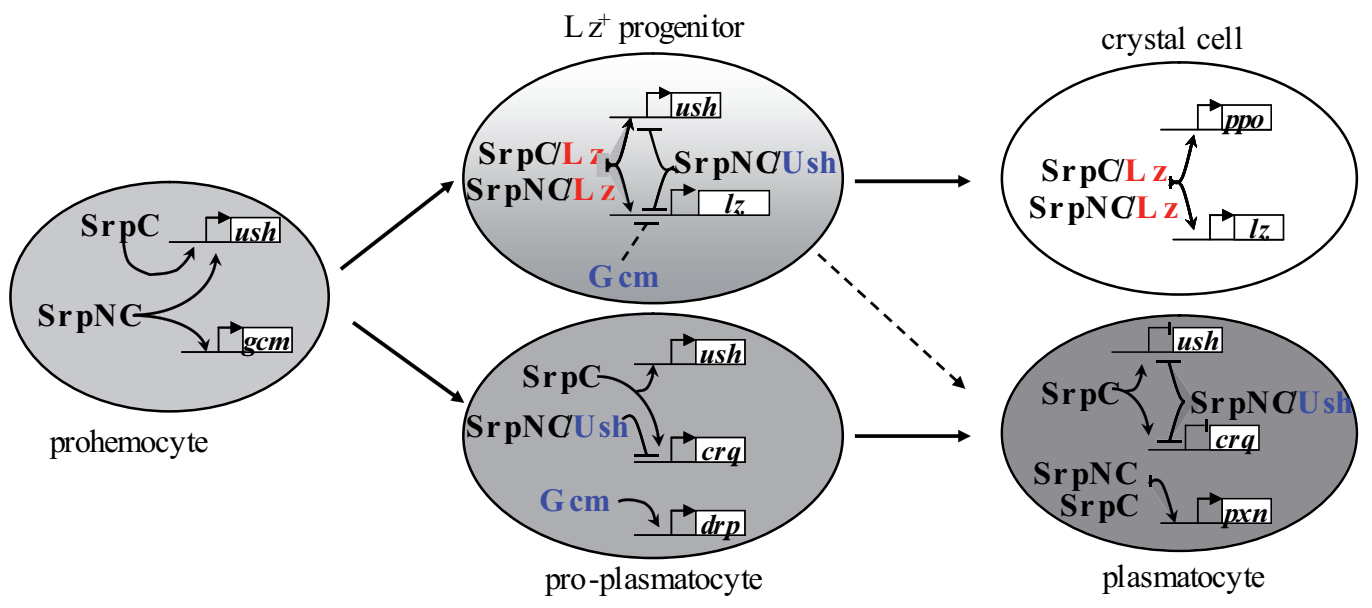

Fig. 1. Transcriptional regulation of embryonic blood cell development. (A) At stage 5, all the prohemocytes express srp and gcm By stage 78, ush expression is activated in all the cells, while gcm expression is switched off and lz expression induced in the anterior row of prohemocytes (red) $\mathrm{Srp}^{+} \mathrm{Gcm}^{+}$Ush ${ }^{+}$cells (90\% of the prohemocytes) differentiate into plasmatocytes that migrate throughout the embryo Among the Lz progenitors, $60 \%$ maintain Iz expression and differentiate into crystal cells that remain clustered around the proventriculus, whereas the remaining $40 \%$ differentiate into plasmatocytes. (B) Schematic representation of the transcription factors regulating the different stages of embryonic blood cell fate decision Some of the target genes regulated by the different combination of transcription factors are indicated. See text for details. 
hemocytes in the head mesoderm (Rehorn etal. 1996; de Velasco et al. 2006) (Fig. 1A) and, at the end of embryogenesis, it is expressed in the lymph gland precursors (Mandal et al.2004). Srp is required for the maintenance of embryonic blood cells as well as for the specification of definitive blood cell progenitors in the lymph gland (Rehorn et al. 1996; Sam et al. 1996; Mandal et al. 2004). Interestingly, these functions of srp are similar to that of GATA-2, which is essential for the development of both primitive and definitive blood cell progenitors in mammals (Fujiwara et al. 2004; Ling et al. 2004; Rodrigues et al. 2005). What controls the onset of srpexpression in the embryonic hematopoietic anlage is not known although its expression partially depends on the early head-patterning genes buttonhead (Yin et al. 1997) and empty spiracle (Bataille, 2006). In the late embryo, the expression of srp in the lymph gland progenitors depends on Notch signalling, which specifies the blood cell fate among the mesodermal precursors (Mandal et al. 2004). Accordingly, the ectopic expression of Srp or an activated Notch in the cardiogenic mesoderm promotes blood cell fate choice (Mandal et al. 2004). Strikingly, a similar Notch/GATA cascade is employed in mammals during the specification of definitive haematopoietic stem cells in the dorsal aorta region (Robert-Moreno et al. 2005; Robert-Moreno et al. 2008).

Second, srpalso controls the differentiation of the three Drosophila blood cell lineages. In the embryo, Srp is still detected in mature plasmatocytes and crystal cells (Sam etal. 1996; Lebestky et al. 2003). The ectopic expression of srpC or srpNCthroughout the mesoderm is sufficient to activate the expression of several plasmatocyte markers and mutations affecting ush affect plasmatocyte differentiation, indicating that srpparticipates in the differentiation of this lineage (Waltzer et al. 2002) (Fig. 1B). Furthermore, srphas a dual role in the crystal cell lineage. On the one hand, SrpNC represses crystal cell fate choice by associating to Ush (Fossett et al. 2001): crystal cell number slightly increases in ushmutant embryos and decreases upon enforced expression of Ush. The mechanism of crystal cell repression by FOG proteins appears to be conserved and might require the transcriptional corepressor CtBP. Indeed mouse FOG-1 and FOG-2, but not a FOG-2 protein unable to interact with CtBP, can impair crystal cell formation (Fossett et al. 2001). On the other hand, srpis required for crystal cell differentiation in conjunction with the RUNX transcription factor Lozenge (Lz, see below) (Fossett et al. 2003; Waltzer et al. 2003) (Fig. 1B). Similarly, in mouse, GATA-3 can either promote or inhibit T helper 2 cells development depending respectively on the absence or presence of FOG-1 (Zhou et al. 2001; Kurata et al. 2002). Of note, Srp expression is lower in differentiating crystal cells than in plasmatocytes or blood cell progenitors (Lebestky et al. 2003), and maintaining high level of Srp in the crystal cells inhibits their differentiation (independently of ush) (Waltzer et al. 2002). Likewise, in mouse, GATA-2 is expressed at high level in haematopoietic progenitors cells but has to be down-regulated for normal erythrocytic differentiation to occur (Persons et al. 1999; Kumano et al. 2001). Thus, GATA level of expression is critical for proper blood cell differentiation.

In the larval lymph gland, Srp is expressed in all blood cells (Lebestky et al. 2003; Jung et al. 2005). Its requirement there for plasmatocyte differentiation has not been studied but several lines of evidence suggest that, as in the embryo, Srp cooperates with Lz to induce larval crystal cell fate (Fossett et al. 2003; Ferjoux et al. 2007). In addition, SrpNC associated to Ush might inhibit lamellocyte differentiation (Sorrentino et al. 2007). Indeed, reducing ush level causes lymph gland hypertrophy and overt lamellocyte differentiation, whereas its overexpression suppresses Hop Tum-l-induced lamellocyte formation (see below). In the lymph gland, Ush is expressed in the plasmatocytes but not in the crystal cells or the prohemocytes. This led to the proposal that Ush might restraint the differentiation of mature plasmatocytes into lamellocytes. However, a lineage relationship between these two cells types has not been demonstrated. Surprisingly, Ush is also strongly expressed in differentiated lamellocytes, but its function here remains unknown (Sorrentino et al. 2007). Hence, Ush might regulate several steps of lammellocyte formation.

All together, it is striking that a single GATA factor perform so many functions at multiple steps of blood cell development. The fine tuning of its expression, the existence of functionally distinct protein isoforms and the presence of lineage-specific partners, are crucial to endow srpwith such a broad range of functions but other levels of regulation likely participate in its mutlitasking activity.

\section{The RUNX transcription factor Lozenge}

lozenge, which encodes a transcription factor of the RUNX family, is required for crystal cell differentiation both in the embryo and in the larva (Rizki et al. 1985; Lebestky et al. 2000). RUNX proteins harbour a conserved 128-amino-acid long DNA binding domain, the Runt domain, as well as a C-terminal WRPY motif that is capable of recruiting transcriptional corepressors of the Groucho/ TLE class (Wheeler et al. 2000). In mammals, all three RUNX factors participate in one or more stages of haematopoiesis (Blyth et al. 2005). In particular, RUNX1 (also known as $A M L$ 1), one of the most frequently mutated gene in human acute myeloid or lymphoid leukaemia, is required for definitive haematopoietic stem cell formation as well as for megakaryocytic maturation and lymphocytic differentiation (North et al. 1999; Ichikawa et al. 2004). Beside $/ z$, there are three other RUNX genes in Drosophila: runt, RunxA and RunxB (Rennert et al. 2003). runt is not implicated in blood cell development while the expression patterns and functions of RunXA/CG1379and RunxB/CG15455are not known. Interestingly, a genome-wide dsRNA screen showed that RunXB (and $s r p$ ) is required for growth and viability of two embryonic hemocyte lines in culture (Boutros et al. 2004). Whether RunxB controls blood cell survival in vivo remains to be established.

Binding of RUNX factors to the RACCRCA consensus DNA sequence is enhanced by dimerisation with members of the CBF $\beta$ family, encoded by brother (bro) and big brother (bgb) in Drosophila (Wheeler et al. 2000; Tahirov et al. 2001). In addition, CBF $\beta$ protects RUNX proteins from degradation by the proteasome (Huang et al. 2001). In mammals, CBF $\beta$ loss of function phenocopies RUNX mutations in the haematopoietic system (Talebian et al. 2007), and translocation affecting CBF $\beta$ are associated to the development of acute myeloid leukaemia in human (Blyth et al. 2005). The functions of bro and bgb in Drosophilablood cells have not been analysed. However, it is worth mentioning that RUNX factors display also CBF $\beta$-independent function (Bollerot et al. 2005; Yokomizo et al. 2008), thus Lz might not require Bro or Bgb to promote crystal cell fate.

In the embryo, $/ z$ expression is first detected in the anteriormost raw of prohemocytes slightly after the onset of srp expres- 
sion (Bataille et al. 2005) (Fig. 1A). Only a fraction of these cells maintains $/ z$ transcription and differentiates into crystal cells whereas the remaining progenitors give rise to plasmatocytes (Lebestky et al. 2000; Bataille et al. 2005). Furthermore, using a temperature-sensitive allele of $z$, it was shown that $z$ is continuously required to maintain crystal cell fate (Lebestky et al. 2000). How exactly $/ z$ is switched on is not known but its expression depends on srpand could be maintained in the crystal cell lineage by an autoregulatory loop (Bataille et al. 2005; Ferjoux et al. 2007; Muratoglu et al. 2007). Contrary to the embryo (Bataille et al. 2005), / $z$ expression in the larval lymph gland is activated in scattered cells by Serrate/Notch signalling, which plays an instructive role for crystal cell differentiation both in the lymph gland and in circulating larval hemocytes (Duvic et al. 2002; Lebestky et al. 2003).

At the molecular level, Lz synergizes with Srp to induce crystal cell fate (Fossett et al. 2003; Waltzer et al. 2003). This functional cooperation is mediated in part by a direct interaction between both isoforms of Srp and Lz (Waltzer et al. 2003) and in part at the level of several crystal cell specific genes (including $/ z$ itself) that harbour a particular cis-regulatory module composed of at least one GATA and one RUNX binding site in close association (Ferjoux et al. 2007; Gajewski et al. 2007; Muratoglu et al. 2007) (Fig. 1B). Both type of binding sites are required for Srp/Lzmediated transactivation in vivo, suggesting that Srp and Lz simultaneously bind their targets (Ferjoux et al. 2007). The synergy between Srp and Lz might rely on cooperative DNA binding and/or on the formation of a transactivating platform (Levine and Tjian, 2003). Alternatively, Srp may already bind these enhancers in the prohemocytes and prime them for activation by Lz. It is striking that the same complex composed of a panhaematopoietic (Srp) and a lineage-specific (Lz) transcription factor is directly involved in maintaining the expression of the lineage-specific partner and in coordinating the expression of a wide array of differentiation markers (Ferjoux et al. 2007). This probably ensures a tight coupling between crystal cell fate choice and differentiation. Interestingly, the interaction between GATA and RUNX transcription factors has been conserved through evolution (Waltzer et al. 2003). Therefore, Srp/Lz cooperation might be used as a paradigm to study how GATA/RUNX complexes regulate transcription and blood cell development from Drosophila to vertebrates. In human, GATA1 and RUNX1 were shown to cooperate during megakaryopoiesis ex vivo (Elagib et al. 2003; Xu et al. 2006) and deregulation of the GATA1/RUNX1 complex activity might be implicated in the development of blood cells disorders such as familial platelet disorders and acute megakaryoblastic leukaemia (Elagib and Goldfarb, 2007).

Further studies indicated that crystal cell fate choice relies on the exquisite balance and cross-regulatory interactions between GATA and its two partners RUNX and FOG. Indeed, Ush, which antagonises crystal cell development, is initially detected in all the prohemocytes including the procrystal cells but its expression in this lineage vanishes by the end of embryogenesis (Fossett et al. 2001) (Fig. 1A). ush is directly activated by Srp (Fossett et al. 2001; Waltzer et al. 2002; Muratoglu et al. 2006) and, unexpectedly, it is further upregulated by Srp/Lz during the initial step of crystal cell commitment (Muratoglu et al. 2006, 2007) (Fig. 1B). Given that Ush, by competing with Lz, interferes with SrpNC/Lzinduced activation of $/ z$ and $u s h$ (Waltzer et al. 2003; Muratoglu et al. 2007), it was proposed that the $\mathrm{Lz}^{+} / \mathrm{Srp}^{+} / \mathrm{Ush}^{+}$population is in a dynamic, bi-potential, regulatory state which resolves into two populations: $\mathrm{Srp}^{+} / \mathrm{Lz}^{+}$(crystal cells) and $\mathrm{Srp}^{+} / \mathrm{Ush}^{+}$(plasmatocytes) (Muratoglu et al. 2006, 2007) (Fig. 1A). Yet, how ushis turned off in the crystal cells is not resolved.

\section{The Glial Cells Missing transcription factors}

Two additional key regulators of plasmatocyte versus crystal cell fate in the embryo are glial cells missing $(\mathrm{gcm})$ and $\mathrm{gcm} 2$ (also known as glide and glide2). $\mathrm{gcm}$ and $\mathrm{gcm} 2$ are the primary determinant of glial cell fate in Drosophila (Jones et al. 1995; Vincent et al. 1996; Kammerer and Giangrande, 2001; Alfonso and Jones, 2002). They encode two related transcription factors with a conserved Gcm-type zinc finger DNA-binding domain that recognizes the DNA sequence 5'-ATGCGGGR-3' (Hashemolhosseini and Wegner, 2004). In the embryo, $\mathrm{gcm}$ is initially expressed throughout the haematopoietic anlage but its expression is rapidly turned off in the Lz+ progenitors (Bataille et al., 2005), while it is transiently maintained in the differentiating plasmatocytes (Bernardoni et al. 1997; Lebestky et al. 2000; Kammerer and Giangrande, 2001; Alfonso and Jones, 2002) (Fig. 1A).

In the absence of both $\mathrm{gcm} / \mathrm{gcm} 2$, plasmatocyte differentiation is severely impaired and their number is strongly reduced (Bernardoni etal. 1997; Kammerer and Giangrande, 2001; Alfonso and Jones, 2002). Conversely, the ectopic expression of $\mathrm{gcm}$ is sufficient to induce the expression of several plasmatocytes markers (Bernardoni et al. 1997; Freeman et al. 2003) and its misexpression in the crystal cells turn them into plasmatocytes (Lebestky et al. 2000), suggesting that $\mathrm{gcm} / \mathrm{gcm} 2$ play an instructive role during plasmatocyte specification similar to their role in gliogenesis (Fig. 1B). Consistent with this idea, several genes expressed in the plasmatocytes contain clusters of Gcm binding sites and depend on $\mathrm{gcm} / \mathrm{gcm} 2$ (Freeman et al. 2003).

In addition, $\mathrm{gcm} / \mathrm{gcm} 2$ mutant embryos display an increase in the number of $L z+$ progenitors and all these progenitors differentiate into crystal cells (as compared to $60 \%$ in the wildtype situation) (Bataille et al. 2005). Thus $\mathrm{gcm} / \mathrm{gcm} 2$ restrict $/ z$ induction in the prohemocytes and interfere with the maintenance of $/ z$ expression in the early $L z+$ progenitors. There are no consensus Gcm binding site in / $z$ hemocyte-specific enhancer and $\mathrm{gcm} / \mathrm{gcm} 2$ might impair / $z$ maintenance indirectly, for instance by promoting ush expression. As mentioned above, gcm can inhibit /zexpression and reprogram crystal cells into plasmatocytes (Lebestky et al. 2000; Bataille et al. 2005). On the opposite, $I z$ is unable to repress $\mathrm{gcm}$ expression and/or plasmatocyte differentiation (Waltzer et al. 2003). Hence crystal cell versus plasmatocyte fate does not rely on reciprocal antagonism between two lineagespecific transcription factors, as it is often observed for alternate blood cell fate choice in vertebrates (Galloway et al. 2005; Rhodes et al. 2005), but it requires additional input to turn-off the priming of the prohemocytes toward the plasmatocyte fate (Bataille et al. 2005).

Of note, neither $\mathrm{gcm}$ nor $\mathrm{gcm} 2$ appear to be expressed in the lymph gland, and which transcription factor controls larval plasmatocyte differentiation is still unknown. Finally, although it was shown that the zebrafish gcmbis expressed in macrophages (Hanaoka et al. 2004), the putative functions of the $\mathrm{gcm}$ homo- 
logues during haematopoiesis in vertebrates have not been studied.

\section{The transcriptional network controlling embryonic blood cell development}

Our current knowledge of the transcriptional network controlling embryonic blood cell development is summarised Fig. 1. srp expression in the head mesoderm initiates at the zygotic transition (stage 5) and is required for blood cell fate specification. In its absence, neither $\mathrm{gcm} / \mathrm{gcm} 2$, ushor $/ z$ transcription is detected in stage 7 embryos. Overexpressing srpthroughout the mesoderm is sufficient to induce ectopic expression of $u s h$ (which was shown to be a direct target gene) and $g c m$ but not $/ z$. The majority of the prohemocytes maintains $s r p, g \mathrm{~cm} / \mathrm{gcm} 2$ and $u s h$ expression until stage 10 and differentiates into plasmatocytes. $\mathrm{Gcm} / \mathrm{Gcm} 2 \mathrm{di}-$ rectly activate the expression of a number of plasmatocyte markers, while Ush associated to SrpNC antagonises SrpC-mediated activation on some srp target genes such as crq to fine tune plasmatocyte differentiation. In the Lz ${ }^{+}$progenitors, Lz associated to Srp promotes its own expression, whereas Ush and Gcm impair $/ z$ autoregulatory loop. We don't know what triggers $/ z$ induction and $g \mathrm{~cm}$ or ush downregulation in these cells, but ultimately only a fraction of them maintain $/ z$ expression. There, Srp and Lz cooperate to activate crystal cell differentiation markers such as the three prophenoloxidase genes.

All together, the resolution of Drosophila embryonic blood cell fate choice relies on the balance and intricate relationships between several transcription factors. Strikingly, it appears that depending on its partners, the GATA factor Srp can promote the two alternate fates. A similar situation has been described during erythro/megakaryocytic differentiation: GATA-1 is expressed in their common progenitor and it is required to promote the two fates (Goldfarb, 2007). It induces megakaryocyte differentiation by associating with Fli-1 and RUNX1, whereas it activates the erythroid program by associating with EKLF. Obviously, several gaps persist in this model. It is expected that future experiments aiming at deciphering the molecular mechanisms of action of these different transcription factors acting either alone or in combination will help bridging these gaps.

\section{Transcription factors controlling larval blood cell de- velopment}

Embryonic haematopoiesis proceeds swiftly with the subdivision of a small mesodermal territory whose progenitors differentiate in a highly stereotypical manner within 14 hours. On the contrary, larval haematopoiesis is a step-wise process that takes place over several days and in a specialised organ that is immune responsive (i.e. blood cell number and differentiation can be regulated by immune challenge). Consequently, this stepwise process implicates several additional signalling pathways and regulatory transcription factors as compared to embryonic haematopoiesis. Yet, as discussed above, Srp and its partners Ush and Lz participate both in embryonic and larval blood cell development. It is tempting to speculate that these transcription factors are a part of an ancestral molecular core underlying the developmment of haematopoietic cell types from invertebrates to vertebrates (Rothenberg and Pant, 2004). Other transcription factors required specifically for larval haematopoiesis might then interact with or regulate this core group of factors to enable the development of a more complex haematopoietic system.

That is the case notably for those controlling the first steps of lymph gland specification and regionalisation. Lymph gland precursors are specified in the lateral mesoderm during mid-embryogenesis. The TALE-class homeodomain transcription factor Homothorax $(\mathrm{Hth})$ is initially expressed ubiquitously in the lymph gland but its expression is subsequently downregulated in the posterior cells as they start to express the HOX factor Antennapedia (Antp) and Collier (Col), the orthologue of mammalian Early B-cell Factor (EBF) (Crozatier et al. 2004; Mandal et al. 2007). These posterior cells prefigure the Posterior Signalling Center (PSC), which plays a key role in maintaining the cells of the medullary zone into a progenitor state in the larval lymph gland (Krzemien et al. 2007; Mandal et al. 2007). co/ is required for PSC cells identity and thus for progenitor blood cell maintenance (Crozatier et al. 2004; Krzemien et al. 2007; Mandal et al. 2007). Its initial expression in the PSC precursors requires antp (Mandal et al. 2007), while its maintenance requires Serrate/Notch signalling (Krzemien et al. 2007). It was proposed that Antp and Hth cross inhibit each other to specify the PSC and the rest of the lymph gland, respectively (Mandal et al. 2007), but the molecular basis for this antagonism remains to be explored. In mammals, Meis1, the homologue of $\mathrm{Hth}$, is also required for definitive haematopoiesis (Hisa et al. 2004; Azcoitia et al. 2005) and it plays a crucial role in leukaemogenesis, notably as a cofactor for Hoxa9 (Zeisig et al. 2004; Wong et al. 2007).

In addition, some transcription factors involved in regulating larval blood cell homeostasis have been identified. First, the STAT DNA binding protein STAT92E and the Gli transcription factor Cubitus interruptus ( $\mathrm{Ci})$, which respectively mediate the transcriptional response to JAK/STAT and Hedgehog signalling, are both required to maintain cells of the medullary zone in a progenitor state in response to the corresponding signals coming from the PSC (Krzemien et al. 2007; Mandal et al. 2007). How these two signalling cascade are integrated at the molecular level to prevent blood cell differentiation has not been investigated yet. Second, the Drosophila Myb transcription factor homologue is required for larval hemocyte proliferation (Davidson et al. 2005). Interestingly, mouse B-Myb rescued blood cell proliferation and differentiation defects of mybmutant larvae, indicating that B-Myb and Drosophila Myb share essential conserved functions. In mammals, $B$-mybplays an ubiquitous role in controlling G2/M cell cycle progression and genome stability (Ramsay and Gonda, 2008) but its role in haematopoiesis has not been thoroughly studied. On the other hand, $c$-myb is involved in leukaemia and it is critical for the expansion of the definitive haematopoietic stem cells as well as for the generation of several blood cell lineages. However, these function of $c-m y b$ might not be conserved in Drosophila myb (Davidson et al. 2005). Third, the Rel/NF-kB transcription factors Dif and Dorsal, which mediate the response to the Toll pathway, also control larval blood cell homeostasis. It has been known for a long time that constitutive activation of the Toll pathway activates blood cell proliferation and induces lamellocyte differentiation (Gerttula et al. 1988; Qiu et al. 1998). More recently, it was shown that Dif and Dorsal are required cell autonomously in circulating hemocytes for efficient phagocytosis and to prevent apoptosis (Matova and Anderson, 2006). Thus the 


\section{L. Waltzer et al.}

Toll/NF- $\kappa \mathrm{B}$ pathway plays an important role in maintaining larval blood cell number. However, the induction of lamellocyte differentiation by constitutively activated Toll/NF- $\kappa B$ signalling might be a secondary event as it is suppressed both in STAT92E and myb mutants (Remillieux-Leschelle et al. 2002; Sorrentino et al. 2004; Davidson et al. 2005). Dif and Dorsal cooperate with Srp and dGATAe to induce antimicrobial peptide expression in the fat body and in the midgut, respectively (Senger et al. 2004, 2006). It is thus tempting to speculate that Dif/Dorsal and Srp might also cooperate to regulate transcription in larval hemocytes.

Finally, some transcription factors affecting larval blood cell differentiation have been identified. As mentioned above, crystal cell differentiation in the larva also depends on $/ z$ (Lebestky et al. 2000) but there its expression is induced in response to Serrate/ Notch signalling (Duvic et al. 2002; Lebestky et al. 2003). Accordingly, Suppressor of Hairless, the transcription factor of the CSL family that regulates Notch target genes, is active in the procrystal cells and required for $/ z$ expression. It is worth noting that crystal cells were absent in larvae lacking $d m y b$, but this phenotype was attributed to a profound defect in proliferation rather than differentiation (Davidson et al. 2005). Mutations in Dif/dorsal affect circulating plasmatocyte function but are not sufficient to suppress their formation (Matova and Anderson, 2006). Similarly, clonal analysis indicated that $m y b^{-/}$plasmatocytes exhibit cell autonomous defect in phagocytosis (Davidson et al. 2005). Actually, it was shown that the differentiation of this lineage requires the receptor tyrosine kinase Pvr, but the transcription factor mediating its effect remains to be discovered. Similarly, the transcriptional network controlling lamellocyte lineage formation is poorly understood. The misexpression in the larval blood cells of several transcription factors such Yan/Aop (Zettervall et al. 2004), Dref (Yoshida et al. 2001), Collier (Crozatier et al. 2004) or Caudal (Hwang et al. 2002) can induce their formation but these gain of function experiments have to be considered with caution. Along the same line, the misexpression of a dominant negative form of the transcription factor Pangolin/dTCF, which mediates Wg/Wnt signalling, or that of an inhibitor of Wg signalling, Shaggy, induces lamellocyte differentiation, suggesting that this particular pathway might be involved in controlling lamellocyte formation (Zettervall et al. 2004). However, no genetic experiments have confirmed this hypothesis so far. Beside ush (see above) (Sorrentino etal. 2007), zygotic mutation in several transcriptional coactivators, corepressor or chromatin remodelling factors also induce lamellocyte formation (Garzino et al. 1992; Kodjabachian et al. 1998; Badenhorst et al. 2002; Bantignies et al. 2002; Remillieux-Leschelle et al. 2002; Minakhina and Steward, 2006). Yet, whether these mutations promote lamellocyte formation in a cell-autonomous manner or reveal a more complex innate immune response is not clear. Indeed, it is known that lamellocyte differentiation can be induced as part of an immune response to "aberrant" self tissues (Dearolf, 1998). Reassessing the function of these genes specifically in the blood cells might shed new light on the control of Drosophila innate immune response.

\section{Concluding remarks}

Although our knowledge of the transcriptional network controlling embryonic and larval blood cell development in Drosophilais still rudimentary, it is striking that most pieces of this network have been conserved in mammals. The relative simplicity of the Drosophila haematopoietic system and the reduced level of gene redundancy facilitate the functional characterisation of each transcription factor controlling the multiple steps of haematopoiesis, from mesodermal progenitors to fully differentiated blood cells. One challenge will be to decipher the combinatorial code that permits blood cell type specific gene expression. Drosophila is a model system amenable both to genetic and biochemical approaches. Their combination should allow to unravel the epistatic and molecular relationships between the members of this network and to discover new factors participating in haematopoiesis from Drosophila to mammals.

\section{Acknowledgments}

We apologise for not citing all the relevant publications due to space restriction. We thank members of our team and of the laboratory for their comments and helpful discussions. This work was supported by grants from the Agence Nationale de la Recherche, the Fondation de France and the Association International for Cancer Research. V.G. and D.O. are supported by fellowships from the Association pour le Recherche contre le Cancer.

\section{References}

ALFONSO TB, JONES BW (2002). gcm2 promotes glial cell differentiation and is required with glial cells missing for macrophage development in Drosophila. Dev Bio/248: 369-383.

AZCOITIA V, ARACIL M, MARTINEZ AC, TORRES M (2005). The homeodomain protein Meis 1 is essential for definitive hematopoiesis and vascular patterning in the mouse embryo. Dev Bio/280: 307-320.

BADENHORST P, VOAS M, REBAY I, WU C (2002). Biological functions of the ISWI chromatin remodeling complex NURF. Genes Dev 16: 3186-3198.

BANTIGNIES F, GOODMAN RH, SMOLIK SM (2002). The interaction between the coactivator dCBP and Modulo, a chromatin-associated factor, affects segmentation and melanotic tumor formation in Drosophila. Proc Nat/Acad Sci USA 99: 2895-2900.

BATAILLE L (2006). Mécanismes de régulation de l'hématopoïèse embryonnaire chez la Drosophile. Thesis in Biologie SantéUniversité Paul Sabatier, Toulouse.

BATAILLE L, AUGE B, FERJOUX G, HAENLIN M, WALTZER L (2005). Resolving embryonic blood cell fate choice in Drosophila: interplay of GCM and RUNX factors. Development 132: 4635-4644.

BERNARDONI R, VIVANCOS B, GIANGRANDE A (1997). glide/gcm is expressed and required in the scavenger cell lineage Dev Bio/191: 118-130.

BLYTH K, CAMERON ER, NEIL JC (2005). The RUNX genes: gain or loss of function in cancer. Nat Rev Cancer 5: 376-387.

BOLLEROT K, ROMERO S, DUNON D, JAFFREDO T (2005). Core binding factor in the early avian embryo: cloning of Cbfbeta and combinatorial expression patterns with Runx1. Gene Expr Patterns 6: 29-39.

BOUTROS M, KIGER AA, ARMKNECHT S, KERR K, HILD M, KOCH B, HAAS SA CONSORTIUM HF, PARO R, PERRIMON N (2004). Genome-Wide RNA Analysis of Growth and Viability in Drosophila. Cells Science 303: 832-835.

CANTOR AB, ORKIN SH (2005). Coregulation of GATA factors by the Friend of GATA (FOG). family of multitype zinc finger proteins. Semin Cell Dev Biol16: 117-128.

CROZATIER, M UBEDA JM, VINCENT A, MEISTER M (2004). Cellular immune response to parasitization in Drosophila requires the EBF orthologue collier. PLOS Biol2: E196.

DAVIDSON CJ, TIROUVANZIAM R, HERZENBERG LA, LIPSICK JS (2005) Functional evolution of the vertebrate Myb gene family: B-Myb, but neither AMyb nor c-Myb, complements Drosophila Myb in hemocytes. Genetics 169: 215-229.

DEAROLF C R (1998). Fruit fly «leukemia». Biochim Biophys Acta 1377: M13-23. 
DE VELASCO B, MANDAL L, MKRTCHYAN M, HARTENSTEIN V (2006). Subdivision and developmental fate of the head mesoderm in Drosophila melanogaster. Dev Genes Evo/216: 39-51.

DUVIC B, HOFFMANN JA, MEISTER M, ROYET J (2002). Notch signaling controls lineage specification during Drosophila larval hematopoiesis. Curr Biol 12: 1923-1927

ELAGIB KE, GOLDFARB AN (2007). Regulation of RUNX1 transcriptional function by GATA-1. Crit Rev Eukaryot Gene Expr17: 271-280.

ELAGIB KE, RACKE FK, MOGASS M, KHETAWATR, DELEHANTY LL, GOLDFARB AN (2003). RUNX1 and GATA-1 coexpression and cooperation in megakaryocytic differentiation. Blood 101: 4333-4341.

EVANS T, FELSENFELD G (1989). The erythroid-specific transcription factor Eryf1: a new finger protein. Ce//58: 877-885

FERJOUX G, AUGE B, BOYER K, HAENLIN M, WALTZER L (2007). A GATA RUNX cis-regulatory module couples Drosophila blood cell commitment and differentiation into crystal cells. Dev Bio/305: 726-734.

FOSSETT N, HYMAN K, GAJEWSKI K, ORKIN SH, SCHULZ RA (2003). Combinatorial interactions of serpent, lozenge, and U-shaped regulate crystal cell lineage commitment during Drosophila hematopoiesis. ProcNat/Acad SciUSA 100: 11451-11456.

FOSSETT N, TEVOSIAN SG, GAJEWSKI K, ZHANG Q, ORKIN SH, SCHULZ RA (2001). The Friend of GATA proteins U-shaped, FOG-1, and FOG-2 function as negative regulators of blood, heart, and eye development in Drosophila. Proc Natl Acad Sci USA 98: 7342-7347.

FOX AH, LIEW C, HOLMES M, KOWALSKI K, MACKAY J, CROSSLEY M (1999). Transcriptional cofactors of the FOG family interact with GATA proteins by means of multiple zinc fingers EMBO J18: 2812-2822

FREEMAN MR, DELROW J, KIM J, JOHNSON E, DOE CQ (2003). Unwrapping glial biology: Gcm target genes regulating glial development, diversification, and function. Neuron 38: 567-580.

FUJIWARA Y, CHANG AN, WILLIAMS AM, ORKIN SH (2004). Functional overlap of GATA-1 and GATA-2 in primitive hematopoietic development. Blood 103: 583-585.

GAJEWSKI KM, SORRENTINO RP, LEE JH, ZHANG Q, RUSSELL M, SCHULZRA (2007). Identification of a crystal cell-specific enhancer of the Black cells prophenoloxidase gene in Drosophila. Genesis 45: 200-207.

GALLOWAY JL, WINGERT RA, THISSE C, THISSE B, ZON LI (2005). Loss of gata1 but not gata2 converts erythropoiesis to myelopoiesis in zebrafish embryos. Dev Cel/8: 109-116.

GARZINO V, PEREIRA A, LAURENTI P, GRABA Y, LEVIS RW, LE PARCO Y, PRADEL J (1992). Cell lineage-specific expression of modulo, a dose-dependent modifier of variegation in Drosophila. EMBO J11: 4471-4479.

GERTTULA S, JIN YS, ANDERSON KV (1988). Zygotic expression and activity of the Drosophila Toll gene, a gene required maternally for embryonic dorsalventral pattern formation. Genetics 119: 123-133.

GOLDFARB AN (2007). Transcriptional control of megakaryocyte development. Oncogene 26: 6795-6802.

HAENLIN M, CUBADDA Y, BLONDEAU F, HEITZLER P, LUTZ Y, SIMPSON P, RAMAIN P (1997). Transcriptional activity of pannier is regulated negatively by heterodimerization of the GATA DNA-binding domain with a cofactor encoded by the u-shaped gene of Drosophila. Genes Dev 11: 3096-3108.

HAENLIN M, WALTZER L (2004). Roles of GATA factors in development In Zinc finger proteins: from atomic contact to cellular function (Eds S. luchi and N. Kuldell). Landes Bioscience, Georgetown. Pp. 221-231

HANAOKA R, OHMORI Y, UYEMURA K, HOSOYA T, HOTTA Y, SHIRAO T, OKAMOTO H (2004). Zebrafish $\mathrm{gcmb}$ is required for pharyngeal cartilage formation. Mech Dev 121: 1235-1247.

HARTENSTEIN V (2006). Blood cells and blood cell development in the animal kingdom. Annu Rev Cell Dev Bio/22: 677-712.

HASHEMOLHOSSEINI S, WEGNER M (2004). Impacts of a new transcription factor family: mammalian GCM proteins in health and disease. J Ce// Bio/166: 765-768.

HISA T, SPENCE SE, RACHE RA, FUJITA M, NAKAMURA T, WARD JM, DEVORHENNEMAN DE, SAIKI Y, KUTSUNA H, TESSAROLLO L, JENKINS NA,
COPELAND, NG (2004). Hematopoietic, angiogenic and eye defects in Meis1 mutant animals. EMBO J23: 450-459.

HUANG G, SHIGESADA K, ITO K, WEE HJ, YOKOMIZO T, ITO Y (2001). Dimerization with PEBP2beta protects RUNX1/AML1 from ubiquitin-proteasomemediated. degradation EMBO J20: 723-733.

HWANG MS, KIM YS, CHOI NH, PARK JH, OH EJ, KWON EJ, YAMAGUCHI M, YOO MA (2002). The Caudal homeodomain protein activates Drosophila E2F gene expression. Nucleic Acids Res 30: 5029-5035.

ICHIKAWAM, ASAIT, SAITO T, YAMAMOTO G, SEO S, YAMAZAKII, YAMAGATA T, MITANI K, CHIBA S, HIRAI H, OGAWA S, KUROKAWA M (2004). AML-1 is required for megakaryocytic maturation and lymphocytic differentiation, but not for maintenance of hematopoietic stem cells in adult hematopoiesis. Nat Med 10, 299-304

JONES BW, FETTER RD, TEAR G, GOODMAN CS (1995). glial cells missing: a genetic switch that controls glial versus neuronal fate. Ce//82: 1013-1023.

JUNG SH, EVANS CJ, UEMURA C, BANERJEE U (2005). The Drosophila lymph gland as a developmental model of hematopoiesis. Development 132: 2521 2533.

KAMMERER M, GIANGRANDE A (2001). Glide2, a second glial promoting factor in Drosophila melanogaster. EMBO J20: 4664-4673.

KO LJ, ENGEL JD (1993). DNA-binding specificities of the GATA transcription factor family. Mo/ Cell Bio/13: 4011-4022.

KODJABACHIAN L, DELAAGE M, MAUREL C, MIASSOD R, JACQ B, ROSSET, R (1998). Mutations in ccf, a novel Drosophila gene encoding a chromosoma factor, affect progression through mitosis and interact with $P_{C}-G$ mutations. EMBO J17: 1063-1075.

Krzemien J, Dubois L, Makki R, Meister M, Vincent A, Crozatier M (2007). CONTROL OF BLOOD CELL HOMEOSTASIS IN Drosophila larvae by the posterior signalling centre Nature 446: 325-328.

KUMANO K, CHIBA S, SHIMIZU K, YAMAGATA T, HOSOYA N, SAITO T, TAKAHASHI T, HAMADA Y, HIRAI H (2001). Notch1 inhibits differentiation of hematopoietic cells by sustaining GATA-2 expression. Blood98: 3283-3289.

KURATA H, LEE HJ, MCCLANAHAN T, COFFMAN RL, O'GARRA A, ARAI N (2002). Friend of GATA is expressed in naive Th cells and functions as a repressor of GATA-3-mediated Th2 cell development. J Immuno/168: 45384545.

LEBESTKY T, CHANG T, HARTENSTEIN V, BANERJEE U (2000). Specification of Drosophila hematopoietic lineage by conserved transcription factors. Science 288:146-149.

LEBESTKY T, JUNG SH, BANERJEE U (2003). A Serrate-expressing signaling center controls Drosophila hematopoiesis. Genes Dev 17: 348-353.

LEVINE M, TJIAN R (2003). Transcription regulation and animal diversity. Nature 424: $147-151$.

LING KW, OTTERSBACH K, VAN HAMBURG JP, OZIEMLAK A, TSAI FY, ORKIN SH, PLOEMACHER R, HENDRIKS RW, DZIERZAK E (2004). GATA-2 plays two functionally distinct roles during the ontogeny of hematopoietic stem cells. $\checkmark$ Exp Med200: 871-882.

MANDAL L, BANERJEE U, HARTENSTEIN, V (2004). Evidence for a fruit fly hemangioblast and similarities between lymph-gland hematopoiesis in fruit fly and mammal aorta-gonadal-mesonephros mesoderm. Nat Genet 36: 10191023.

MANDAL L, MARTINEZ-AGOSTO JA, EVANS CJ, HARTENSTEIN V, BANERJEE U (2007). A Hedgehog- and Antennapedia-dependent niche maintains Drosophila haematopoietic precursors. Nature 446: 320-324

MARTIN DI, ORKIN SH (1990). Transcriptional activation and DNA binding by the erythroid factor GF-1/NF-E1/Eryf 1. Genes Dev 4: 1886-1898.

MATOVA N, ANDERSON KV (2006). Rel/NF-kappaB double mutants reveal that cellular immunity is central to Drosophila host defense. Proc Nat/Acad Sci USA 103: 16424-16429.

MERIKA M, ORKIN SH (1993). DNA-binding specificity of GATA family transcription factors. Mol Cell Biol13: 3999-4010.

MINAKHINA S, STEWARD R (2006). Melanotic mutants in Drosophila: pathways and phenotypes. Genetics 174: 253-263.

MURATOGLU S, GARRATT B, HYMAN K, GAJEWSKI K, SCHULZ RA, FOSSETT 


\section{L. Waltzer et al.}

N (2006). Regulation of Drosophila friend of GATA gene, u-shaped, during hematopoiesis: a direct role for serpent and lozenge. Dev Bio/296: 561-579.

MURATOGLU S, HOUGH B, MON ST, FOSSETT N (2007). The GATA factor Serpent cross-regulates lozenge and u-shaped expression during Drosophila blood cell development. Dev Bio/311: 636-649.

NORTH T, GU TL, STACY T, WANG Q, HOWARD L, BINDER M, MARIN-PADILLA $M$, SPECK NA (1999). Cbfa2 is required for the formation of intra-aortic hematopoietic clusters. Development 126: 2563-2575.

OMICHINSKI J, CLORE G, SCHAAD O, FELSENFELD G, TRAINOR C, APPELLA E, STAHL S, GRONENBORN A (1993). NMR structure of a specific DNA complex of zn-containing DNA binding domain of GATA-1. Science 261: 438446.

PANG L, XUE HH, SZALAI G, WANG X, WANG Y, WATSON DK, LEONARD WJ, BLOBEL GA, PONCZ M (2006). Maturation stage-specific regulation of megakaryopoiesis by pointed-domain Ets proteins. Blood 108: 2198-2206.

PERSONS DA, ALLAY JA, ALLAY ER, ASHMUN RA, ORLIC D, JANE SM, CUNNINGHAM JM, NIENHUIS AW (1999). Enforced expression of the GATA2 transcription factor blocks normal hematopoiesis. Blood 93: 488-499.

QIU P, PAN PC, GOVIND S (1998). A role for the Drosophila Toll/Cactus pathway in larval hematopoiesis. Development 125: 1909-1920.

RAMSAY RG, GONDA TJ (2008). MYB function in normal and cancer cells. Nat Rev Cancer 8: 523-534.

REHORN KP, THELEN H, MICHELSON AM, REUTER R (1996). A molecular aspect of hematopoiesis and endoderm development common to vertebrates and Drosophila. Development 122: 4023-4031.

REMILLIEUX-LESCHELLE N, SANTAMARIA P, RANDSHOLT NB (2002). Regulation of larval hematopoiesis in Drosophila melanogaster. a role for the multi sex combs gene. Genetics 162: 1259-1274.

RENNERT J, COFFMAN JA, MUSHEGIAN AR, ROBERTSON AJ (2003). The evolution of Runxgenes I. A comparative study of sequences from phylogenetically diverse model organisms. BMC Evol Bio/3: 4.

RHODES J, HAGEN A, HSU K, DENG M, LIU TX, LOOK AT, KANKI JP (2005). Interplay of pu1 and gata1 determines myelo-erythroid progenitor cell fate in zebrafish. Dev Cel/8: 97-108.

RIZKITM, RIZKIRM, BELLOTTIRA (1985). Genetics of a Drosophilaphenoloxidase. Mol Gen Genet 201: 7-13.

ROBERT-MORENO A, ESPINOSA L, DE LA POMPA JL, BIGAS A (2005). RBPjkappa-dependent Notch function regulates Gata2 and is essential for the formation of intra-embryonic hematopoietic cells. Development 132: 11171126.

ROBERT-MORENO A, GUIUJ, RUIZ-HERGUIDO C, LOPEZME, INGLES-ESTEVE J, RIERA L, TIPPING A, ENVER T, DZIERZAK E, GRIDLEY T, ESPINOSA L, BIGAS A (2008). Impaired embryonic haematopoiesis yet normal arterial development in the absence of the Notch ligand Jagged1. EMBO J27: 18861895.

RODRIGUES NP, JANZEN V, FORKERT R, DOMBKOWSKI DM, BOYD AS, ORKIN SH, ENVER T, VYAS P, SCADDEN DT (2005). Haploinsufficiency of GATA-2 perturbs adult hematopoietic stem-cell homeostasis. Blood106: 477484.

ROTHENBERG EV, PANT R (2004). Origins of lymphocyte developmental programs: transcription factor evidence. Semin Immuno/ 16: 227-238.

SAM S, LEISE W, HOSHIZAKI DK (1996). The serpent gene is necessary for progression through the early stages of fat-body development. Mech Dev60: 197-205.

SENGER K, ARMSTRONG GW, ROWELL WJ, KWAN JM, MARKSTEIN M, LEVINE M (2004). Immunity regulatory DNAs share common organizational features in Drosophila. Mol Cel/13: 19-32.

SENGER K, HARRIS K, LEVINE M (2006). GATA factors participate in tissuespecific immune responses in Drosophila larvae. Proc Natl Acad Sci USA 103: 15957-15962.

SHIMIZU R, YAMAMOTO M (2005). Gene expression regulation and domain function of hematopoietic GATA factors. Semin Cel/ Dev Biol16: 129-136.

SORRENTINO RP, MELK JP, GOVIND S (2004). Genetic analysis of contributions of dorsal group and JAK-Stat92E pathway genes to larval hemocyte concentra- tion and the egg encapsulation response in Drosophila. Genetics 166: 13431356.

SORRENTINO RP, TOKUSUMI T, SCHULZ RA (2007). The Friend of GATA protein U-shaped functions as a hematopoietic tumor suppressor in Drosophila. Dev Bio/311: 311-323.

TAHIROV TH, INOUE-BUNGO T, MORII H, FUJIKAWA A, SASAKI M, KIMURA K SHIINA M, SATO K, KUMASAKA T, YAMAMOTO M, ISHII S, OGATA K (2001) Structural analyses of DNA recognition by the AML1/Runx-1 Runt domain and its allosteric control by CBFbeta. Cel/104: 755-767.

TALEBIAN L, LI Z, GUO Y, GAUDET J, SPECK ME, SUGIYAMA D, KAUR P, PEAR WS, MAILLARD I, SPECK NA (2007). T-lymphoid, megakaryocyte, and granulocyte development are sensitive to decreases in CBFbeta dosage. Blood109: 11-21.

TRAINOR CD, GHIRLANDO R, SIMPSON MA (2000). GATA zinc finger interactions modulate DNA binding and transactivation. J Biol Chem 275: 28157 28166

TRAINOR CD, OMICHINSKI JG, VANDERGON TL, GRONENBORN AM, CLORE GM, FELSENFELD G (1996). A palindromic regulatory site within vertebrate GATA-1 promoters requires both zinc fingers of the GATA-1 DNA-binding domain for high-affinity interaction. Mol Cel/ Bio/16: 2238-2247.

TSANG AP, FUJIWARA Y, HOM DB, ORKIN SH (1998). Failure of megakaryopoiesis and arrested erythropoiesis in mice lacking the GATA-1 transcriptional cofactor FOG. Genes Dev12: 1176-1188.

TSANG AP, VISVADER JE, TURNER CA, FUJIWARA Y, YU C, WEISS MJ, CROSSLEY M, ORKIN SH (1997). FOG, a multitype zinc finger protein, acts as a cofactor for transcription factor GATA-1 in erythroid and megakaryocytic differentiation. Cel/90: 109-119.

VINCENT S, VONESCH JL, GIANGRANDE A (1996). Glide directs glial fate commitment and cell fate switch between neurones and glia. Development 122 131-139.

WALTZER L, BATAILLE L, PEYREFITTE S, HAENLIN M (2002). Two isoforms of Serpent containing either one or two GATA zinc fingers have different roles in Drosophila haematopoiesis. EMBO J21: 5477-5486.

WALTZER L, FERJOUX G, BATAILLE L, HAENLIN M (2003). Cooperation between the GATA and RUNX factors Serpent and Lozenge during Drosophila hematopoiesis. EMBO J22: 6516-6525.

WANG X, CRISPINO JD, LETTING DL, NAKAZAWA M, PONCZ M, BLOBEL, GA (2002). Control of megakaryocyte-specific gene expression by GATA-1 and FOG-1: role of Ets transcription factors. EMBO J21: 5225-5234.

WHEELER JC, SHIGESADA K, GERGEN JP, ITO Y (2000). Mechanisms of transcriptional regulation by Runt domain proteins. Semin Ce// Dev Bio/11: 369 375 .

WHYATT DJ, DEBOER E, GROSVELD, F (1993). The two zinc finger-like domains of GATA-1 have different DNA binding specificities. EMBO J12: 4993-5005.

WONG P, IWASAKI M, SOMERVAILLE TC, SO CW, CLEARY ML (2007). Meis 1 is an essential and rate-limiting regulator of MLL leukemia stem cell potential. Genes Dev 21: 2762-2774.

XU G, KANEZAKI R, TOK, T, WATANABE $S$, TAKAHASHI $Y$, TERUI $K$, KITABAYASHI I, ITO E (2006). Physical association of the patient-specific GATA1 mutants with RUNX1 in acute megakaryoblastic leukemia accompanying Down syndrome. Leukemia 20: 1002-1008.

YAMAMOTO M, KO LJ, LEONARD MW, BEUG H, ORKIN SH, ENGEL JD (1990) Activity and tissue-specific expression of the transcription factor NF-E1 multigene family. Genes Dev 4: 1650-1662.

YIN Z, XU XL, FRASCH M (1997). Regulation of the twist target gene tinman by modular cis-regulatory elements during early mesoderm development. Deve/ opment 124: 4971-4982.

YOKOMIZOT, HASEGAWA K, ISHITOBIH, OSATO M, EMAM, ITOY, YAMAMOTO M, TAKAHASHI S (2008). Runx1 is involved in primitive erythropoiesis in the mouse. Blood 111: 4075-4080.

YOSHIDA H, INOUE YH, HIROSE F, SAKAGUCHIK, MATSUKAGEA, YAMAGUCH M (2001). Over-expression of DREF in the Drosophila wing imaginal disc induces apoptosis and a notching wing phenotype. Genes Cel/s 6: 877-886.

ZEISIG BB, MILNE T, GARCIA-CUELLAR MP, SCHREINER S, MARTIN ME, FUCHS U, BORKHARDT A, CHANDA SK, WALKER J, SODEN R, HESS JL, 
SLANY RK (2004). Hoxa9 and Meis1 are key targets for MLL-ENL-mediated cellular immortalization. Mo/ Cel/ Bio/24: 617-628.

ZETTERVALL CJ, ANDERL I, WILLIAMS MJ, PALMER R, KURUCZ E, ANDO I, HULTMARK, D (2004). A directed screen for genes involved in Drosophilablood cell activation. Proc Natl Acad Sci USA 101: 14192-14197.

ZHOU M, OUYANG W, GONG Q, KATZ SG, WHITE JM, ORKIN SH, MURPHY KM (2001). Friend of GATA-1 represses GATA-3-dependent activity in CD4+ T cells. J Exp Med 194: 1461-1471.

\section{Further Related Reading, published previously in the Int. J. Dev. Biol.}

See our recent Special Issue Placenta edited by Joan S. Hunt and Kent L. Thornburg at: http://www.ijdb.ehu.es/web/contents.php?vol=54\&issue=2-3

A novel role of the glial fate determinant glial cells missing in hematopoiesis Cécile Jacques, Laurent Soustelle, István Nagy, Céline Diebold and Angela Giangrande Int. J. Dev. Biol. (2009) 53: 1013-1022

Tracing the hemangioblast during embryogenesis: developmental relationships between endothelial and hematopoietic cells Thierry Jaffredo, Karine Bollerot, Daisuke Sugiyama, Rodolphe Gautier and Cécile Drevon

Int. J. Dev. Biol. (2005) 49: 269-277

Of birds and mice: hematopoietic stem cell development

Isabelle Godin and Ana Cumano

Int. J. Dev. Biol. (2005) 49: 251-257

\section{Embryonic development of the human hematopoietic system}

Manuela Tavian and Bruno Péault

Int. J. Dev. Biol. (2005) 49: 243-250

Multilineage hematopoietic progenitor activity generated autonomously in the mouse yolk sac: analysis using angiogenesisdefective embryos

Christine Rampon and Philippe Huber

Int. J. Dev. Biol. (2003) 47: 273-280

Pathways in blood and vessel development revealed through zebrafish genetics

Philip S Crosier, Maggie L Kalev-Zylinska, Christopher J Hall, Maria Vega C Flores, Julia A Horsfield and Kathryn E Crosier Int. J. Dev. Biol. (2002) 46: 493-502

Embryonic stem cells and transgenic mice in the study of hematopoiesis

$\mathrm{S} \mathrm{H}$ Orkin

Int. J. Dev. Biol. (1998) 42: 927-934
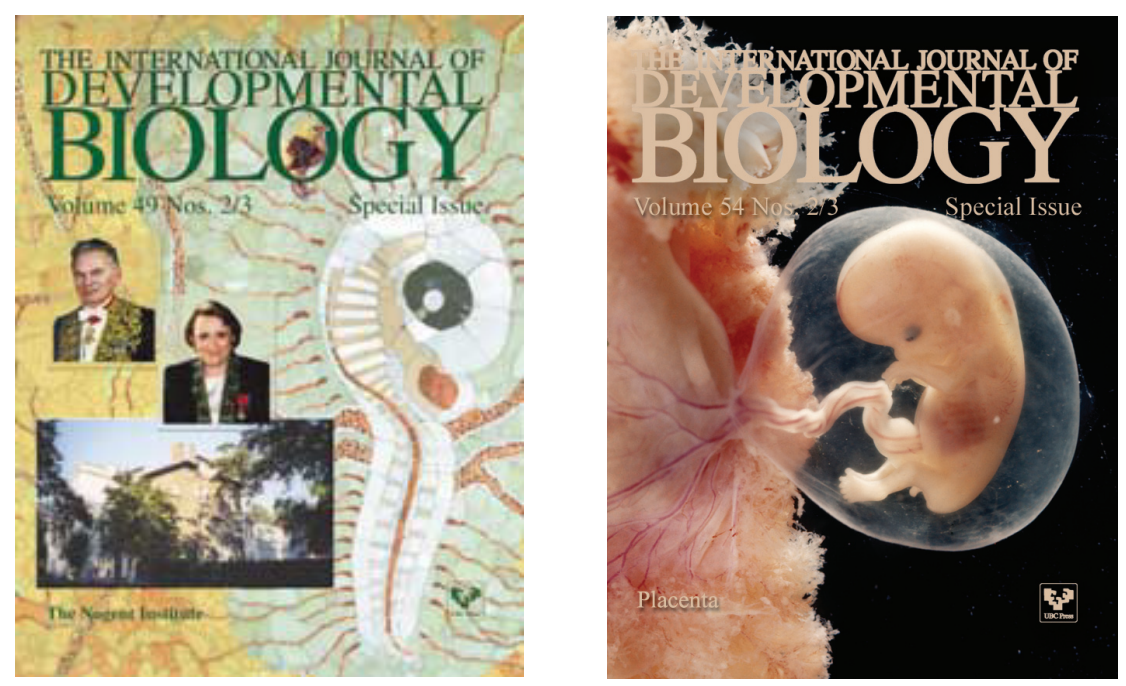

5 yr ISI Impact Factor $(2009)=3.253$
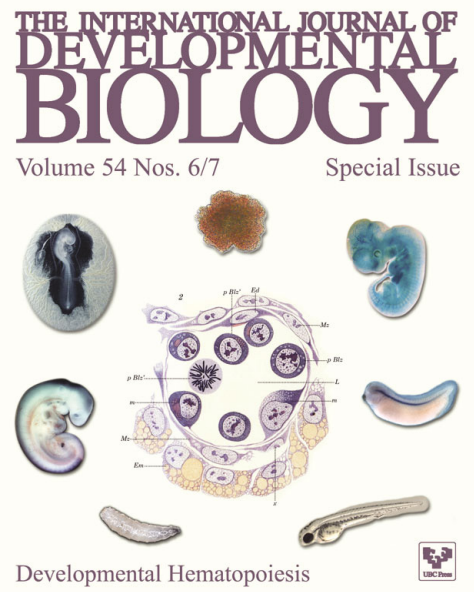